\title{
A DEMONSTRAÇÃO DO FLUXO DE CAIXA COMO INSTRUMENTO DE GERENCIAMENTO E CONTROLE FINANCEIRO PARA AS MICRO E PEQUENAS EMPRESAS
}

\section{A STATEMENT OF CASH FLOW AS MANAGEMENT TOOL AND FINANCIAL CONTROL FOR MICRO AND SMALL BUSINESSES}

Recebido: 05/08/2015 - Aprovado: 16/10/2015 - Publicado: 29/12/2015 Processo de Avaliação: Double Blind Review

\author{
Eloir Trindade Vasques Vieira ${ }^{1}$ \\ Mestre em Desenvolvimento Local \\ Docente da UCDB - Universidade Católica Dom Bosco \\ eloir@ucdb.br \\ Janaina Vareiro da Costa Batistoti \\ Pós-graduanda em Contabilidade Financeira e Controladoria \\ Graduada em Ciências Contábeis \\ UCDB - Universidade Católica Dom Bosco \\ janainavareiro@hotmail.com
}

\begin{abstract}
RESUMO: No ambiente atual, onde a competitividade está presente em vários cenários, se faz necessário que as empresas tenham um maior controle de suas informações financeiras, ou seja, o quanto se gasta e o quanto se tem em caixa. Desta forma, o administrador necessita de ferramentas que possam auxiliá-lo nessa análise, para que se tenha uma visão detalhada sobre os recursos financeiros que a organização dispõe. Assim apresentou se a demonstração do fluxo de caixa, que não é só um relatório exigido por lei para grandes empresas, mas também pode ser utilizado como uma ferramenta de gerenciamento e controle financeiro para qualquer empresa, bem como se utilizado como instrumento de gestão, pode ser capaz de apontar direções para a tomada de decisão também nas pequenas e médias empresas. Observou-se por meio de uma simulação que a Demonstração do fluxo de Caixa é de grande importância e que de maneira mais simplificada, o empreendedor pode utilizar esse recurso para visualizar suas saídas de recursos, podendo com isso ter maior controle sobre suas finanças, além de ser um instrumento de planejamento financeiro, dando suporte a toda a organização.
\end{abstract}

PALAVRAS-CHAVE: Demonstração do Fluxo de Caixa; Gerenciamento; Controle; Planejamento.

ABSTRACT: In the current environment, where competition is present in various scenarios, it is necessary that companies have greater control of your financial information, ie how much is spent and how much you have on hand. Thus, the administrator needs tools that can help you in

\footnotetext{
${ }^{1}$ Autora para correspondência: UCDB: Av. Tamandaré, 6000 - Jardim Seminário, Campo Grande - MS, Brasil. CEP 79117-900.
} 
this analysis, in order to have a detailed look at the financial resources that the organization offers. Thus presented the statement of cash flow, which is not only a report required by law for large companies, but can also be used as a management and financial control tool for any business and is used as a management tool, can be able to point directions for decision making also in small and medium-sized enterprises. It was observed through a simulation that the cash flow statement is of great importance and more simply, the entrepreneur can use this feature to preview your resource outputs and can thus have greater control over their finances, besides being a financial planning tool, supporting the entire organization.

KEYWORDS: 1 Cash Flow Statement. 2 management. 3 Control. 4 Planning.

\section{INTRODUÇÃO}

Tanto nas organizações quanto na vida pessoal, o planejamento torna-se fundamental para que se possa atingir objetivos. Planejar é de extrema importância para as empresas que querem manter-se competitivas e atuantes no mercado. Desse modo, torna-se muito mais difícil lidar com uma situação imprevista, pois talvez não haja tempo ou recurso disponível para que a reação seja adequada àquela situação.

Com isso, faz-se necessário a utilização de métodos e ferramentas que auxiliem o administrador em suas tomadas de decisões e caminhos a serem seguidos na empresa. A Demonstração do Fluxo de Caixa (DFC) é de grande valia nesses casos, pois é o instrumento que dá ao gestor financeiro a possibilidade de planejar, controlar, prever, e organizar os recursos financeiros da organização para um determinado período.

A DFC não é obrigatória para empresas com capital social menor que o valor de $\mathrm{R} \$ 2.000 .000,00$ (dois milhões de reais) na data de encerramento do balanço patrimonial, todavia pode ser elaborada de maneira mais simples, apenas para atender a fins gerenciais, como o controle do caixa da empresa. Utilizado neste caso a última legislação em vigor (BRASIL, 2007).

Essa gestão do fluxo de caixa visa prever acontecimentos estranhos ao controle da empresa, como a falta de recursos em determinado período, ou mesmo a necessidade de capital de terceiros para expansão do negócio.

O trabalho apresentará o fluxo de caixa, como instrumento de auxilio e controle junto às micro e pequenas empresas. Trata-se de uma pesquisa bibliográfica. 


\section{A GESTÃO DO FLUXO DE CAIXA}

Manter um controle financeiro eficiente se faz necessário para a sobrevivência das empresas, seja ela de grande, médio ou pequeno porte. O fluxo de caixa nasce como uma ferramenta própria para a gestão dos recursos da empresa, isto é, todas as transações de receitas, despesas ou investimentos podendo ser controlados através dessa ferramenta.

Para Zdanowicz (1992, p. 37), o fluxo de caixa é assim definido:

Denomina-se fluxo de caixa de uma empresa ao conjunto de ingressos e desembolsos de numerário ao longo de um período determinado. O fluxo de caixa consiste na representação dinâmica da situação financeira de uma empresa, considerando todas as fontes de recursos e todas as aplicações em itens do ativo.

O autor Segundo Filho (2005, p.35) resume o fluxo de caixa como sendo "um instrumento indispensável de planejamento financeiro, sem o qual muitas delas ficam com um barco a deriva sem saber o seu rumo".

Isso demonstra que o fluxo de caixa serve como um guia, apresentando a real situação do caixa e direcionando o melhor caminho a seguir.

Assaf Neto e Silva (2012, p. 39) conceituam o fluxo de caixa como "um instrumento que relaciona os ingressos e saídas (desembolsos) de recursos monetários no âmbito de uma empresa em determinado período".

No período econômico do século XXI, em que a concorrência exige cada vez mais uma gestão eficiente dos recursos da empresa, a gestão do fluxo de caixa é de grande auxilio para o gestor financeiro, pois permite que sejam acompanhados permanentemente os resultados da organização, promovendo assim um controle maior do desempenho, ajustes e correções necessários ao bom funcionamento da empresa (ASSAF NETO; SILVA, 2012).

O fluxo de caixa apresenta-se como uma bússola para as organizações, devido ao seu poder de apontar qual o rumo financeiro deverá ser seguido em determinado momento. Nas várias transações que a empresa faz, como compra, venda, empréstimos e alienações, é necessário que todas as suas dívidas sejam pagas no momento do seu respectivo vencimento, para isso deve-se apresentar saldo de caixa disponível no momento da liquidação. A falta de dinheiro em caixa pode propiciar a organização corte 
no crédito, insuficiência de estoque para atender aos clientes, acarretando alterações nas operações da companhia (TÓFOLI, 2008).

Todas as transações que a empresa executa durante seu ciclo operacional devem ser monitoradas pelo gestor financeiro, para que a companhia tenha ciência de sua média de vendas no mês, seu fluxo de recebimento e pagamento. Com isso a empresa consegue controlar com maior fidedignidade seus recursos financeiros.

A gestão do fluxo de caixa não representa um caixa com níveis elevados de sobra de recursos, mas sim propicia uma folga financeira para a empresa, fazendo com que suas obrigações sejam liquidadas no momento certo. A sobra de caixa em altos níveis não é um fator bom a ser demonstrado, ao contrário disso, apresenta-se como um problema para a gestão financeira, já que o dinheiro em excesso no caixa da organização poderia estar sendo aplicado em outras atividades, gerando com isso maior lucratividade. Para que haja uma gestão competente, é de extrema importância que o administrador financeiro saiba avaliar criteriosamente seu ciclo operacional, uma vez que possuindo conhecimento necessário, saberá avaliar qual nível de caixa deverá ser mantido, para que não haja nem sobra e nem falta de recursos para manter suas atividades (ASSAF NETO; SILVA, 2012).

Verifica-se com isso que é de suma importância que o administrador financeiro tenha conhecimento das ferramentas existentes para o correto controle do caixa da empresa. O planejamento, controle e o fluxo de caixa devem ser implantados em conjunto, já que assim apresentarão melhores resultados para a organização.

\section{ADMINISTRAÇÃO FINANCEIRA E PLANEJAMENTO}

Para que uma empresa continue em operação, conforme reza o princípio da continuidade, é importante, que ela possua um controle financeiro, que se busque quanto há disponível para que consiga liquidar suas obrigações.

Um aliado de grande valia para a companhia, a informação financeira traz dados para que o gestor financeiro saiba lidar com as situações impostas pelo mercado dos negócios.

Nos dias atuais, a competitividade do mundo corporativo obriga as empresas a manterem seu caixa com certa liquidez, pois com isso tornam-se agressivas para competir 
por melhores preços, uma vez que pagando a vista ou com prazo menor, tem muitas chances de obterem um menor preço.

Desta forma a informação financeira pode ser uma ferramenta de grande relevância dentro da instituição, visto que possuindo conhecimento sobre a saúde financeira da azienda, o administrador poderá traçar projetar e implantar estratégias para cada tipo de situação.

Para Silva (2010, p.3), a administração financeira compreende:

\begin{abstract}
Gerenciar os recursos financeiros para obter lucros, dessa forma maximiza a riqueza dos acionistas. Ela pode ser exercida nas mais variadas organizações, tais como: indústrias, comércio ou serviços, empresas estatais ou privadas voltadas ou não para fins lucrativos.
\end{abstract}

A administração financeira busca assegurar um melhor processo de captação e alocação das finanças empresariais, por esse motivo ela trabalha tanto com escassez de recursos como com a sobra, orientando e definindo as políticas da gestão financeira.

Com o intuito de maximização dos recursos e diminuição dos custos e despesas, o administrador tem como objetivo visualizar a empresa como um todo, buscando não só a captação de fundos para a empresa, bem como o gerenciamento dos recursos adquiridos a fim de manter a saúde financeira da organização, como também atingir suas metas e objetivos. Assim sendo, pode-se afirmar que a área financeira não busca somente atingir níveis esperados de caixa, mas também influenciar na tomada de decisão dos gestores. (ASSAF NETO, 2014).

Vários autores reforçam que o planejamento é o primeiro passo para a elaboração do fluxo de caixa, pois neste primeiro momento serão evidenciados os erros, problemas e dificuldades que a empresa pode enfrentar, alertando o gestor nas decisões que deverão ser tomadas, para que não haja nenhum imprevisto ou insuficiência de recursos.

Silva (2010, p.28), enfatiza que "o planejamento envolve decisões em relação ao futuro, visando identificar e avaliar as melhores alternativas e suas consequências, incluindo os riscos".

Contudo, o planejamento não visa somente às insuficiências de caixa, mas também a sobras, pois se o planejamento for realizado no inicio de cada período ou ciclo 
operacional, e for detectado que haverá um superávit no caixa da organização, sugere-se que deva ser alocada de modo a gerar maior lucratividade, como por exemplo, deixá-la rendendo em aplicações financeiras, ou utiliza-la para amortização de dívidas que por ventura a empresa tenha.

Ross, Westerfield e Jaffe (2011, p.589), definem planejamento financeiro como sendo "um processo que ajuda a empresa a evitar tropeçar no futuro caminhando para trás". Antes de tudo, é necessário definir os caminhos a serem seguidas pela empresa, quais as oportunidades que deverão ser aproveitadas, qual o grau de endividamento a empresa está disposta a ter, além do quanto pensa reinvestir a médio e longo prazo. Estas são opções financeiras que a empresa deverá decidir para que tenha crescimento e rentabilidade.

Ademais, para que seja uma ferramenta eficaz para a empresa, o planejamento financeiro deve envolver conjuntos de premissas, com cenários de piora, melhora ou estáveis. A organização necessita estar preparada para um momento de inflação, alta dos juros ou queda nas vendas, visto que muitos desses casos influenciam negativamente o caixa da organização.

Além disso, um bom planejamento financeiro deve conter alguns elementos fundamentais, como a previsão de vendas, ou seja, uma visão aproximada de quanto se pretende vender num determinado período.

Outro fator importante são as demonstrações projetadas, pois vislumbram as perspectivas do balanço futuro, bem como da demonstração do fluxo de caixa. As possíveis necessidades de ativos ou financiamentos também são de extrema importância para o plano financeiro, pois detectam os gastos possíveis com capital, ou se haverá necessidade de capital de terceiros para cobrir as despesas da instituição (ROSS, WESTERFIELD, JAFFE 2011).

Assim, observa-se que a administração financeira e o planejamento são grandes aliados para uma boa gestão, que visa atingir as metas, objetivos e o crescimento da instituição. Com essas ferramentas o gestor financeiro poderá planejar as decisões futuras da empresa, sem correr o risco de não possuir instrumentos para guiá-lo em suas decisões e escolhas. Através do planejamento é que se tem conhecimento das adversidades que serão enfrentadas pela companhia, podendo assim minimizar ou até mesmo eliminar as dificuldades e crises. 


\section{A DEMONSTRAÇÃO DO FLUXO DE CAIXA}

Com o advento da Lei 11.638/2007, a demonstração do fluxo de caixa (DFC) tornou-se obrigatório para as companhias de capital aberto ou empresas que possuam, na data de encerramento do balanço, patrimônio líquido igual ou superior a $R$ \$2.000.000,00 (dois milhões de reais). (BRASIL, 2007).

Segundo WARREN, REEVE e FESS (2008, p.468), a demonstração do fluxo de caixa:

Relata as principais entradas e saídas de caixa durante um determinado período de tempo. Ela fornece informações úteis sobre a capacidade da empresa em gerar caixa operacional, manter e expandir sua capacidade operacional, cumprir com suas obrigações financeiras e pagar dividendos.

A DFC demonstra aos usuários internos e externos a capacidade que a empresa possui de gerar caixa e seus equivalentes, bem como o emprego desses recursos.

Ferreira (2012, p. 899), diz que a demonstração do fluxo de caixa "evidencia as modificações ocorridas nas disponibilidades da companhia, em um determinado exercício".

Na demonstração do fluxo de caixa não é analisado somente o caixa, que são os numerários em espécie, ou a conta bancos conta movimento, mas também seus correspondentes, que são os chamados "equivalentes de caixa", que compreendem as aplicações financeiras de liquidez imediata, de curto prazo, que são conversíveis em caixa de imediato sem sofrer variações bruscas de valor. Com isso, a DFC não evidencia somente as variações sofridas no caixa da organização, mas também verifica as mudanças ocorridas nas demais disponibilidades (FERREIRA, 2012).

A DFC foi introduzida de maneira a facilitar o entendimento de seus usuários, pois substituiu a Demonstração de Origens e Aplicações de Recursos (DOAR), considerado um relatório completo e rico em detalhes, porém de difícil entendimento para muitos usuários, já a DFC foi elaborada de maneira mais simples e objetiva, de modo a facilitar a compreensão dos números apresentados (BRASIL, 2007).

Uma das melhores ferramentas financeiras para o gestor financeiro, do mesmo modo que para os investidores e demais interessados nas finanças da empresa, a DFC 
consegue demonstrar com clareza a capacidade da empresa em liquidar suas dívidas, bem como para avaliarem a situação financeira da companhia, por meio de operações passadas e que podem influenciar em um planejamento futuro (WARREN, REEVE, FESS; 2008).

Através da DFC, pode-se verificar se a empresa foi autossuficiente, ou seja, se não necessitou de capital de terceiros para honrar com suas obrigações, igualmente se há possibilidade de expansão com capital próprio, são alguns dos objetivos da demonstração.

Matarazzo (2010, p. 364), enumera também como objetivos da Demonstração do Fluxo de Caixa:

1. Avaliar alternativas de investimento;

2. Avaliar e controlar ao longo do tempo as decisões importantes que são tomadas na empresa, com reflexos monetários;

3. Avaliar as situações presente e futura do caixa na empresa, posicionando-a para que não chegue a situação de iliquidez;

4.Certificar que os excessos momentâneos de caixa estão sendo devidamente aplicados.

Neste sentido, pode-se afirmar que a DFC tornou-se uma peça de grande valor para que a empresa mantenha sua saúde financeira. Ela traz consigo informações preciosas que levam o administrador a repensar caminhos ou soluções, avaliar novos investimentos e aferir o desempenho financeiro da companhia.

\subsection{FORMAS DE APRESENTAÇÃO DA DEMONSTRAÇÃO DO FLUXO DE CAIXA}

De acordo com a Lei 11.638/2007, a DFC deve demonstrar as mudanças ocorridas no caixa e equivalentes de caixa durante o exercício. $\mathrm{O}$ art.188 da Lei 11.638/2007 estabelece a segregação de, no mínimo, três fluxos:

I - demonstração dos fluxos de caixa - as alterações ocorridas, durante o exercício, no saldo de caixa e equivalentes de caixa, segregando-se essas alterações em, no mínimo, 3(três) fluxos:

a)Das operações;

b)Dos financiamentos; e

c)Dos investimentos;

Segundo Ferreira (2012), para que seja feita de forma correta, a segregação dos fluxos deve considerar inicialmente a atividade principal exercida pela empresa, visto que 
em uma companhia cuja principal atividade seja financeira, como um banco, a classificação dos empréstimos e financiamentos será classificada como fluxo operacional, e não como atividades de financiamento.

Além disso, é relevante a observância da classificação dos equivalentes de caixa, que são mantidos com finalidade específica de atender pagamentos de curto prazo, sendo assim, investimentos em outras sociedades não devem ser considerados como equivalentes de caixa.

Quadro 1 - Fluxo de caixa e suas atividades.

\begin{tabular}{|c|l|}
\hline Fluxo de Caixa & \multicolumn{1}{c|}{ Principais Alterações } \\
\hline Das Atividades Operacionais & $\begin{array}{l}\text { São transações que afetam o lucro líquido. Exemplos de tais } \\
\text { transações incluem a compra e a venda de mercadorias por um } \\
\text { varejista. }\end{array}$ \\
\hline $\begin{array}{c}\text { Das Atividades de } \\
\text { Investimento }\end{array}$ & $\begin{array}{l}\text { São transações que afetam os investimentos em ativos } \\
\text { permanentes. Exemplos de tais transações incluem a venda e a } \\
\text { compra de ativos fixos, como equipamentos e edifícios. }\end{array}$ \\
\hline $\begin{array}{c}\text { Das atividades de } \\
\text { Financiamento }\end{array}$ & $\begin{array}{l}\text { longo prazo das empresas. Exemplos dessas transações incluem } \\
\text { a emissão ou o resgate de títulos, como ações e obrigações. }\end{array}$ \\
\hline
\end{tabular}

Fonte: Adaptado de Warren, Reeve, Fess, 2008, p.468.

Na elaboração dos fluxos de caixa, geralmente são apresentadas as atividades operacionais, seguidas das atividades de investimento e por fim as atividades de financiamento. O fluxo de caixa líquido resultante de cada saldo de caixa dessas atividades demonstra se houve aumento ou diminuição do caixa no período. O saldo inicial do caixa é somado ao aumento ou diminuição líquido de caixa do período, o resultado representa o saldo final de caixa do período, que deverá ser igual ao apresentado no balanço patrimonial (WARREN, REEVE, FESS 2008).

Conforme Ferreira (2012), o fluxo operacional é relacionado diretamente com a produção e a venda dos produtos e serviços da empresa, ou seja, das principais atividades geradoras de lucro para a organização, além das transações não enquadradas como de investimento ou financiamento.

As principais atividades de entradas e saídas do fluxo operacional são descritas por Ferreira (2012, p. 900), como sendo: 
1. Recebimentos das vendas à vista de bens, serviços e royalties e das contas a receber correspondentes, na hipótese de vendas a prazo;

2. Recebimentos de Juros decorrentes de empréstimos e financiamentos concedidos ou de aplicações financeiras em geral; e recebimentos de dividendos e juros sobre o capital próprio derivados de participação no capital de outras sociedades;

3. Outros recebimentos que não sejam originários de transações definidas como atividades de investimento ou financiamento, como por exemplo, recebimentos decorrentes de sentenças judiciais e indenizações por sinistros, exceto as indenizações diretamente relacionadas a atividades de investimento ou financiamento.

As atividades são desmembradas devido a grande variação que pode ocorrer nas transações de uma empresa, por esse motivo há necessidade de se agrupar elementos da mesma natureza. As atividades de entrada do fluxo operacional são as principais geradoras de receita da empresa. Estão relacionadas com a produção de bens ou serviços, ou as operações que não se enquadrem em atividade de investimento ou financiamento.

Saídas:

1. Pagamentos a fornecedores de mercadorias, matérias-primas e outros insumos de produção;

2. Pagamentos a empregados e aos demais fornecedores de serviço;

3. Pagamentos de impostos, taxas, contribuições e multas aos governos federal, estaduais e municipais;

4. Pagamentos dos juros (despesas financeiras) dos empréstimos e financiamentos obtidos, e de dividendos e juros sobre o capital próprio. O pagamento do principal dos empréstimos e financiamentos obtidos deve ser apresentado entre as atividades de financiamento.

O fluxo de caixa das atividades de investimento compreende as compras de ativos de longo tempo de vida útil, bem como os desembolsos referentes a transações financeiras, como a concessão e recebimento de empréstimos e financiamentos. $\mathrm{O}$ recebimento na alienação de participações em outras sociedades e na alienação de títulos de investimentos podem ser exemplos das entradas dos fluxos de investimento. Os desembolsos dos empréstimos concedidos, o pagamento na compra de títulos patrimoniais de outras sociedades, são exemplos de fluxo de investimentos de saída (FERREIRA, 2012).

As atividades relacionadas à captação de recursos dos proprietários ou acionistas, ou a captação de empréstimos de terceiros são exemplos de atividades de financiamentos. 
Warren, Reeve e Fess, (2008, p.470), ainda exemplificam as entradas e saídas das atividades de financiamento "entradas incluem emissões de debêntures, de títulos a pagar e de ações preferenciais e ordinárias. As saídas de caixa das atividades de financiamento incluem o pagamento de dividendos, o resgate de títulos de dívida e a aquisição de parte de suas ações".

A figura 1 demonstra as transações que são habitualmente utilizadas nos fluxos:

Figura 1 - Fluxo de Caixa

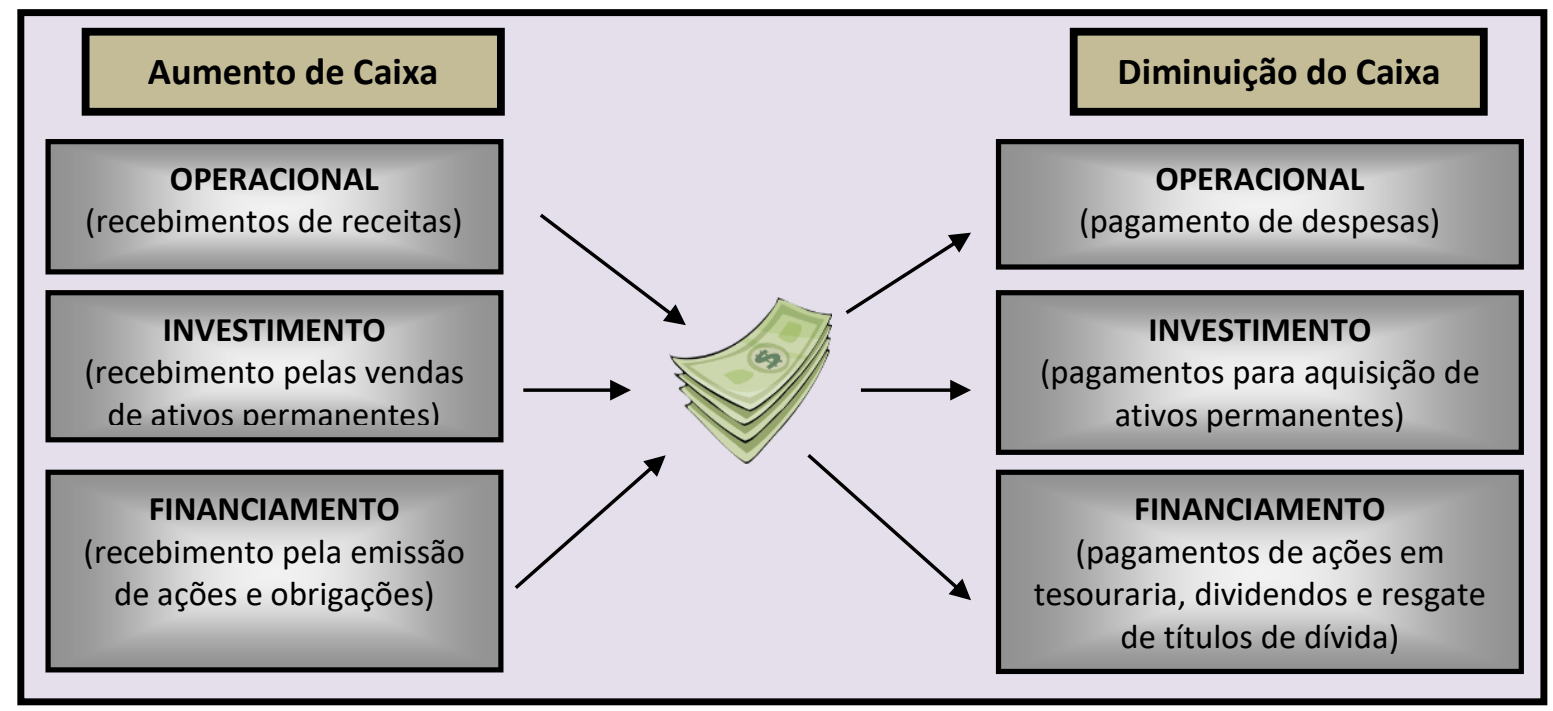

Fonte: Warren, Reeve, Fess, 2008, p. 469.

Ao analisar a figura acima, observa-se que existe uma relação recebimento de receitas pode estar relacionado ao pagamento das despesas, quando ambos se enquadram na atividade operacional. O impacto de cada uma das três atividades é identificado em separado. Com isso o gestor consegue visualizar com maior facilidade qual das operações está lhe gerando maior lucro ou prejuízo.

Portanto, a demonstração dos Fluxos de Caixa tem como objetivo principal prover informações acerca dos recebimentos e pagamentos, em caixa ou equivalente de caixa, em determinado período e segregando esses fluxos em atividades, o que se torna interessante para analise não somente do todo, mas avaliando-as por frações. Essa observação é importante, porque demonstra se a empresa está sendo independente com seus recursos, isto é, se necessitou de aporte de terceiros, ou mesmo qual sua capacidade de expansão com recursos próprios. 


\section{MICRO E PEQUENAS EMPRESAS NO BRASIL}

As micro e pequenas empresas - MPE desempenham papel importante na economia brasileira, e ao longo dos últimos 30 anos, houve um crescente aumento no número das MPEs, e este crescimento veio acompanhado da significante função exercida por estas empresas. Os dados contidos a seguir comprovam essa informação nas várias extensões do Brasil (SEBRAE, 2014 p. 7):

\footnotetext{
a)As MPE geraram, em 2011, 27,0\% do valor adicionado do conjunto de atividades pesquisadas (PIB);

b)Esse percentual vem aumentando na série histórica, iniciada em 1985, quando esse indicador representava de $21,0 \%$ do valor adicionado (PIB), e em 2001, 23,2\%;

c)Serviços e comércio representaram, em 2011, $19 \%$ do valor adicionado (PIB), e em 2001, 23,2\%;

d)Em relação ao número de empresas as MPE representaram, em 2011, nas atividades de serviços e de comércio, respectivamente, $98 \%$ e $99 \%$ do total de empresas formalizadas;

e)Em relação ao emprego, as MPE representavam $44 \%$ dos empregos formais em serviços, e aproximadamente $70 \%$ dos empregos gerados no comércio;

f)Cerca de $50 \%$ das remunerações do setor formal de comércio foram pagas, em 2011, por MPE.
}

Os dados ratificam a importância do segmento das micro e pequenas empresas para o país, fomentando a geração de empregos, o crescimento da renda em nível nacional, e ainda, o aumento do produto interno bruto (PIB). Ainda verificando a importância das MPEs, a geração de empregos relacionados a esse setor só tendem a aumentar, pois em 2011, metade dos salários pagos no setor formal foi feito pela micro e pequena empresa.

A definição de enquadramento das Micro e Pequenas Empresas tem uma variedade de critérios, na qual pode ser utilizada como critério de delimitação a Legislação específica das MPEs, as instituições financeiras oficiais e os órgãos representativos desse segmento. 
Tabela 1 - Classificação dos pequenos negócios.

\begin{tabular}{|c|c|c|}
\hline \multicolumn{2}{|c|}{ Porte } & Faturamento Bruto Anual \\
\hline \multicolumn{2}{|c|}{ Microempreendedor individual } & Até $\mathrm{R} \$ 60 \mathrm{mil}$ \\
\hline \multirow{2}{*}{ MPE } & Microempresa (ME) & Até R\$ 360 mil \\
\hline & Empresa de Pequeno porte (EPP) & Acima de $\mathrm{R} \$ 360$ mil até $\mathrm{R} \$ 3,6$ milhões \\
\hline
\end{tabular}

Fonte: Adaptado de SEBRAE/SP 2014.

O Quadro 2 demonstra o critério adotado para o enquadramento das micro e pequenas empresas no Brasil com base no faturamento anual:

O microempreendedor individual pode ser conceituado como o pequeno empresário optante pelo simples nacional que trabalha por conta própria e tem sua empresa registrada, ou melhor, legalizada. Pela lei, este pequeno empresário não pode possuir vínculo com mais de um empregado e também não pode ser sócio ou titular da empresa.

A microempresa (ME) é definida, como sendo a empresa devidamente registrada nos órgãos competentes, juntamente com o dono da empresa, que aufira em cada ano calendário, a receita bruta igual ou inferior a $\mathrm{R} \$ 360.000,00$ (trezentos e sessenta mil reais). Da mesma forma se dá a empresa de pequeno porte (EPP), porém o faturamento passa ser superior a $\mathrm{R} \$ 360.000,00$ (trezentos e sessenta mil reais) e igual ou inferior a R \$ 3.600.000,00 (três milhões e seiscentos mil reais). (BRASIL, 2011).

Buscando o não fechamento destas empresas, faz-se necessário a utilização de ferramentas contábeis, como a demonstração do fluxo de caixa, para o maior controle das entradas e principalmente das saídas de caixa, para que o gestor tenha conhecimento do que mais afeta seu caixa, podendo assim controlar de maneira efetiva os gastos ocorridos e com isso maximizar seu lucro.

\section{ELABORAÇÃO DE FLUXO DE CAIXA DE UMA MPE.}

A Demonstração do fluxo de caixa é uma demonstração financeira exigida por lei, para empresas com capital social igual ou superior a $\mathrm{R} \$ 2.000 .000,00$ (dois milhões) na data de encerramento do balanço, porém isso não significa que as empresas de pequeno e médio porte não possam elaborar a DFC, para fins de controle e gerenciamento. 
$\mathrm{O}$ comitê de pronunciamentos contábeis emitiu pronunciamento técnico $\mathrm{n}^{\mathrm{o}} 03$, demonstrando as normas para sua preparação. A Demonstração dos Fluxos de Caixa demonstra as entradas e saídas do caixa e equivalentes de caixa, além de apresentar a situação financeira da empresa e sua capacidade de honrar seus compromissos. Muitos questionamentos podem ser sanados através da DFC, pois a demonstração responde a questões de obtenção de dinheiro, ou onde o dinheiro foi aplicado e com qual objetivo (CARDOSO et al., 2015).

Tomando-se um fluxo de caixa de uma empresa fictícia, apresentado nas tabelas 2 e 3, pode-se efetuar análise do comportamento da situação financeira de uma empresa de pequeno porte.

Dados da empresa XY:

Tabela 2- Exemplo de Empresa Fictícia XY - Parte 1.

\begin{tabular}{l|c}
\hline 1. Constituição da empresa XY em dinheiro & 1.500 \\
\hline 2. Abertura de uma conta corrente no banco XX & 580 \\
\hline 3. Compra de um imóvel à vista, conforme cheque 001; & 200 \\
\hline 4. Compra de móveis e utensílios à vista, conforme cheque 002; & 300 \\
\hline 5. Compra, para revenda, de 10 aparelhos produto BB a R\$ 70,00, cada, a prazo. & 700 \\
\hline 6. Venda de 5 aparelhos de um produto BB a R\$ 90,00 cada, à vista & 450 \\
\hline 7. Depósito no banco da XX & 400 \\
\hline 8. Pagamento de diversas despesas, cheque 003 & 120 \\
\hline 9. Aplicação em um fundo de investimentos não considerado equivalente a caixa & 350 \\
\hline 10. Pagamento de Fornecedor, a prazo. & \\
\hline
\end{tabular}

Observação: Os números apresentados estão considerados sem moeda específica. Fonte: Elaborado pelas Autoras. 
Tabela 3- Exemplo de Empresa Fictícia XY - Parte 2.

\begin{tabular}{|c|c|c|c|c|c|c|c|c|c|c|}
\hline & Caixa & Banco & Imóveis & Móveis & Mercad. & Fl. & $=$ & Fornec & $\begin{array}{l}\text { Capital } \\
\text { Social }\end{array}$ & Resultado \\
\hline Constituição & 1.500 & & & & & & $=$ & & 1.500 & \\
\hline Abert. C/C & $(580)$ & 580 & & & & & $=$ & & & \\
\hline Aq. Imóvel & & (200) & 200 & & & & $=$ & & & \\
\hline Aq. M.U & & $(300)$ & & 300 & & & $=$ & & & \\
\hline Aq. Mercad & & & & & 700 & & $=$ & 700 & & \\
\hline Vend. $5 \mathrm{Tv}$ & 450 & & & & & & $=$ & & & 450 \\
\hline Baixa prod. & & & & & $(350)$ & & $=$ & & & $(350)$ \\
\hline Depósito & $(400)$ & 400 & & & & & $=$ & & & \\
\hline Pag. D. Div. & & (120) & & & & & $=$ & & & (120) \\
\hline Aplic. FI & & $(350)$ & & & & 350 & $=$ & & & \\
\hline $\begin{array}{c}\text { Pagto } \\
\text { Fornec. }\end{array}$ & (290) & & & & & & $=$ & (290) & & \\
\hline Total & 680 & 10 & 200 & 300 & 350 & 350 & $=$ & 410 & 1.500 & (20) \\
\hline
\end{tabular}

Observação: Os números apresentados estão considerados sem moeda específica.

Fonte: Elaborado pelas Autoras.

Todos os pagamentos e recebimentos foram realizados por meio da conta corrente da empresa aberta no banco XX.

Conforme demonstrado, a constituição da empresa foi feita em dinheiro, no valor de 1.500. Foi realizada a transferência de 580 do caixa para abertura da conta corrente, além disso, foi efetuado o pagamento da aquisição de imóveis no valor de 200, bem como a compra de móveis e utensílios no valor de 300 . Houve também a aquisição de 10 aparelhos, para revenda, totalizando assim o valor de 700 com aquisição de mercadoria.

O evento seguinte foi o depósito no banco XX, no valor de 400, que saiu da conta caixa, ocorreu também o pagamento de despesas diversas no valor de 120, que foi pago com cheque à vista. Foi aplicado em um fundo de investimento não considerado como equivalente de caixa o valor de 350, como também o pagamento à vista para fornecedor no valor de 290. Considerando receitas e despesas, a empresa XY totalizou 
um prejuízo contábil no valor de 20 conforme Demonstração do Resultado do Exercício DRE apresentado na tabela 4:

Tabela 4- Demonstração do Resultado do Exercício Receita Bruta

(-) Deduções da Receita

$$
\begin{gathered}
\frac{450}{0} \\
\hline 0 \\
\hline 350) \\
\hline
\end{gathered}
$$

(=) Receita Líquida

(-) Custo das Mercadorias Vendidas

$=$ Lucro Bruto

(-) Despesas Operacionais =Lucro Operacional

Observação: Os números apresentados estão considerados sem moeda específica. Fonte: Elaborado pelas Autoras.

A demonstração do Resultado do exercício vislumbra contas de resultado, e apresenta o saldo apurado em relação às operações realizadas pela empresa em seu ciclo operacional. A DRE é elaborada pelo princípio da competência, ou seja, as receitas e despesas devem ser incluídas na apuração do resultado do exercício em que ocorrerem, não importando a data de pagamento ou recebimento. Além disso, a DRE inclui as depreciações e amortizações para apurar seu resultado.

A seguir, será evidenciado a Demonstração do Fluxo de Caixa, na tabela 5: 
Tabela 5- Demonstração do Fluxo de Caixa

\begin{tabular}{|c|c|}
\hline FLUXO DE CAIXA DA ATIVIDADE OPERACIONAL & \\
\hline Recebimento de Clientes & 450 \\
\hline Pagamento a Fornecedores & $(290)$ \\
\hline Pagamento de despesas diversas & $(120)$ \\
\hline Total FCO & 40 \\
\hline \multicolumn{2}{|l|}{ FLUXO DE CAIXA DA ATIVIDADE DE INVESTIMENTO } \\
\hline Pagamento Aquisição de imóvel & $(200)$ \\
\hline Pagamento Aquisição de Móveis & $(300)$ \\
\hline Aplicação no fundo de investimentos & $(350)$ \\
\hline Total FCI & $(\mathbf{8 5 0})$ \\
\hline \multicolumn{2}{|l|}{ FLUXO DE CAIXA DA ATIVIDADE DE FINANCIAMENTO } \\
\hline Integralização de Capital Social & 1.500 \\
\hline Distribuição de Dividendos & 0 \\
\hline Total FCF & 1.500 \\
\hline Variação do Caixa e equivalente & 690 \\
\hline Saldo Inicial do Caixa e equivalente & $\mathbf{0}$ \\
\hline Saldo Final do Caixa e Equivalente & 690 \\
\hline
\end{tabular}

Observação: Os números apresentados estão considerados sem moeda específica.

Fonte: Elaborado pelas Autoras.

Verifica-se que o saldo final do caixa e equivalentes foi de 690 positivo, enquanto a DRE apresentou um lucro operacional negativo. Isso se deve ao fato de que as empresas seguem o regime de competência, reconhecendo receitas quando auferidas, ou seja, nem sempre quando recebidas, da mesma forma que as despesas quando incorridas.

Desse modo, o lucro operacional apresentado na DRE, muitas vezes não apresenta o real fluxo de caixa operacional do período. A demonstração dos fluxos de caixa é a única demonstração financeira que é elaborada por meio do regime de caixa, que significa que os pagamentos e os recebimentos são reconhecidos unicamente quando se recebe ou se paga por meio de dinheiro ou equivalente.

Pode-se observar também que enquanto os fluxos de atividade operacional e de financiamentos geraram um caixa positivo, o fluxo de investimento gerou um caixa negativo, pois houveram mais saídas do que entradas. Este é um exemplo em que a DFC pode orientar o administrador financeiro em sua tomada de decisão, pois neste caso ele poderia controlar melhor as saídas de dinheiro com a aquisição de imóveis ou aplicações. 
No fluxo de caixa operacional, nota-se que a entrada de recursos foi para cobrir pagamentos com fornecedores e despesas diversas, isso pode demonstrar que a empresa necessita ficar mais atenta a quanto está comprometendo de suas entradas para pagar despesas operacionais, pois desse modo pode ficar descoberta em algum momento, bem como se verifica que se acaso não houvesse a entrada de recursos referente à integralização do capital social, o fluxo de caixa dessa empresa resultaria em um fluxo negativo de recursos.

Conclui-se com essa análise, o quão importante é a DFC para apontar dados da obtenção e aplicação de recursos da empresa, assim como determinar seu sucesso ou fracasso.

\section{CONSIDERAÇÕES FINAIS}

É notório o crescente surgimento de empresas de pequeno e médio porte existentes no Brasil, que competem muitas vezes, com empresas que possuem melhor infraestrutura, tecnologia e com maior capacidade de investimento. Para se sobressair e continuar competitivas diante de um mercado de tantas mudanças é necessário que haja um gerenciamento eficiente dos recursos disponíveis

Para o bom funcionamento da empresa na área financeira, o controle entre receitas e despesas é indispensável, assim como o equilíbrio financeiro entre as entradas e saídas de recursos. Com um bom gerenciamento financeiro é possível planejar, organizar, coordenador e dirigir com competência os recursos financeiros da azienda, gerando assim maior lucratividade.

Não se pode afirmar que utilizando controles financeiros, o risco de dificuldades financeiras seja nulo. Porém, a visão antecipada de entradas e saídas de recursos, podem influenciar o empreendedor a tomar decisões mais acertadas, como exemplo, se o administrador financeiro verificar que se investir em longo prazo na aquisição de um imóvel lhe trará um impacto negativo no saldo de caixa, ou até mesmo que com essa atitude fique impossibilitado de honrar seus compromissos, e certo que irá repensar sua decisão. 
Hoje, várias são as ferramentas disponíveis para o controle financeiro de uma empresa, entre eles, a demonstração do fluxo de caixa, que pode ser uma alternativa para o gerenciamento dos recursos da empresa.

O objetivo do trabalho foi atingido que foi demonstrar a DFC ao usuário as movimentações ocorridas no caixa e seus equivalentes em determinado período, portanto evidenciou se que essa demonstração não visa demonstrar o lucro, mas sim à variação líquida ocorrida no caixa em determinado período, bem como conhecer as circunstâncias para as variações de caixa e avaliar de maneira efetiva se a posição financeira da empresa melhorou e se será capaz de quitar suas dividas no futuro.

Verifica-se também que por ser uma demonstração obrigatória apenas para grandes empresas, torna-se pouco utilizada pelas pequenas empresas, que muitas vezes desconhecem esse recurso. Mesmo sendo dispensada de ser elaborada pelas MPEs, para fins gerenciais a DFC torna-se grande aliada do pequeno empreendedor, por ser de simples elaboração e de fácil compreensão, além de demonstrar com maior clareza onde estão sendo aplicados os recursos da empresa.

\section{REFERENCIAS}

ASSAF NETO, Alexandre. Finanças Corporativas e Valor. 7. ed. São Paulo: Atlas, 2014.

ASSAF NETO, Alexandre; SILVA, César Augusto Tibúrcio. Administração do Capital de Giro. 4. ed. São Paulo:Atlas,2012.

BRASIL. Lei 11.638, de 28 de Dezembro de 2007. Altera e revoga dispositivos da Lei ${ }^{\circ}$ 6.404, de 15 de dezembro de 1976, e da Lei $\mathrm{n}^{\circ}$ 6.385, de 7 de dezembro de 1976, e estende às sociedades de grande porte disposições relativas à elaboração e divulgação de demonstrações financeiras. Disponível em:< http://www.planalto.gov.br/ccivil_03/_ato2007-2010/2007/lei/111638.htm>. Acesso em: 28 out. 2015.

BRASIL. Lei Complementar 139, de 10 de Novembro de 2011. Altera e revoga dispositivos da Lei Complementar $\mathrm{n}^{\circ}$ 123, de 14 de dezembro de 2006, e dá outras providências. Disponível em: <http://www.planalto.gov.br/ccivil_03/leis/LCP/Lcp139.htm>. Acesso em: 04 nov. 2015.

CARDOSO, Ricardo Lopes et al.Contabilidade Geral: Introdução a Contabilidade Societária e Contabilidade Gerencial.4.ed. São Paulo: Atlas, 2015. 
FERREIRA, Ricardo J. Contabilidade Básica: finalmente você vai aprender contabilidade: teoria e 500 questões comentadas. 9. ed. Rio de Janeiro:Ferreira,2012.

JORDAN, Bradford D., ROSS, Stephen A.; WESTERFIELD, Randolph W. Princípios da Administração Financeira. 2. ed. São Paulo:Atlas,2010.

MATARAZZO, Dante Carmine. Análise Financeira de Balanços - Abordagem Gerencial. 7. ed. São Paulo:Atlas,2010.

ROSS, Stephen A.; WESTERFIELD, Randolph W. e JAFFE, Jeffrey F. Administração financeira. Tradução: Antonio Zoratto Sanvicente. 2. ed. 7. reimpr. São Paulo: Atlas, 2011..

SEBRAE, Participação das Micro e Pequenas Empresas na Economia Brasileira. Brasília: Sebrae, 2014. Disponível em:

<http://www.sebrae.com.br/Sebrae/Portal\%20Sebrae/Estudos\%20e\%20Pesquisas/Particip acao $\% 20$ das $\% 20$ micro $\% 20 \mathrm{e} \% 20$ pequenas $\% 20$ empresas.pdf $>$. Acesso em: 30 out.2015.

SEBRAE, Classificação dos pequenos negócios, segundo o faturamento bruto anual. Disponível em:

<http://www.sebraesp.com.br/arquivos_site/biblioteca/EstudosPesquisas/mpes_numeros/ MPE_conceito_faturamento.pdf>. Acesso em: 30 out. 2015.

SEBRAE, Entenda as distinções entre microempresa, pequena empresa e MEI.

Disponível em: <http://www.sebrae.com.br/sites/PortalSebrae/artigos/Entenda-asdistin $\% \mathrm{C} 3 \% \mathrm{~A} 7 \% \mathrm{C} 3 \% \mathrm{~B} 5$ es-entre-microempresa,-pequena-empresa-e-MEI $>$. Acesso em: 21 out. 2015.

SEGUNDO FILHO, José. Controles financeiros e fluxo de caixa. Rio de Janeiro: Qualitymark, 2005.

SILVA, José Pereira. Análise Financeira das empresas. 10. ed. São Pulo: Atlas, 2010.

TÓFOLI, Irso. Administração Financeira Empresarial - Uma tratativa prática.

Campinas: Arte Brasil Editora/Unisalesiano, 2008.

WARREN, Carl S.; REEVE, James M.; FESS, Philip E. Contabilidade Gerencial. 2. ed. São Paulo: Thomson Learning,2008.

ZDANOWICZ, José Eduardo. Fluxo de Caixa: uma decisão de planejamento e controle financeiros. 5. ed. Porto Alegre: Sagra, 1992. 